\title{
Evolution of implantation technique and indications for a subcutaneous cardioverter-defibrillator: over 7 years of experience in Poland
}

\author{
Maciej Kempa', Andrzej Przybylski2,3, Szymon Budrejko', Wojciech Krupa4', Krzysztof Kaczmarek5, Mateusz Ostręga ${ }^{6}$, \\ Paweł Syska ${ }^{7}$, Adam Sokal ${ }^{8}$, Marcin Grabowski ${ }^{9}$, Dariusz Jagielski10 ${ }^{10}$ Maciej Grymuza ${ }^{11}$, Janusz Romanek ${ }^{2,3}$, Stanisław \\ Tubek $^{12}$, Marcin Janowski13, Zbigniew Orski14, Joanna Zakrzewska-Koperska15, Adrian Stanek ${ }^{16}$, Michał Orszulak ${ }^{17}$
}

\author{
'Department of Cardiology and Electrotherapy, Medical University of Gdansk, Gdańsk, Poland \\ ${ }^{2}$ Cardiology Department with the Acute Coronary Syndromes Subdivision, Clinical Provincial Hospital No. 2, Rzeszów, Poland \\ ${ }^{3}$ Medical College, University of Rzeszow, Rzeszów, Poland \\ ${ }^{4}$ Collegium Medicum, Nicolaus Copernicus University, Bydgoszcz, Poland \\ ${ }^{5}$ Department of Electrocardiology, Medical University of Lodz, Łódź, Poland \\ ${ }^{6} 3^{\text {rd }}$ Department of Cardiology, Faculty of Medical Sciences in Zabrze, Medical University of Silesia, Katowice, Poland \\ ${ }^{7} 2^{\text {nd }}$ Department of Arrhythmia, National Institute of Cardiology, Warszawa, Poland \\ ${ }^{8} 1^{\text {st }}$ Department of Cardiology and Angiology, Silesian Centre of Heart Diseases, Zabrze, Poland \\ ${ }_{9}^{9} 1^{\text {st }}$ Chair and Department of Cardiology, Medical University of Warsaw, Warszawa, Poland \\ ${ }^{10}$ Department of Cardiology, Centre for Heart Diseases, $4^{\text {th }}$ Military Hospital, Wrocław, Poland \\ ${ }^{11} 1^{\text {st }}$ Department of Cardiology, Chair of Cardiology, Poznan University of Medical Sciences, Poznań, Poland \\ ${ }^{12}$ Department of Heart Diseases, Wroclaw Medical University, Wrocław, Poland \\ ${ }^{13}$ Chair and Department of Cardiology Medical University of Lublin, Lublin, Poland \\ ${ }^{14}$ Department of Cardiology and Internal Diseases, Military Institute of Medicine, Warszawa, Poland \\ ${ }^{15} 1^{\text {st }}$ Department of Arrhythmia, National Institute of Cardiology, Warszawa, Poland \\ ${ }^{16}$ Department of Electrocardiology, John Paul II Hospital, Kraków, Poland \\ ${ }^{17} 1^{\text {st }}$ Department of Cardiology, School of Medicine in Katowice, Medical University of Silesia, Katowice, Poland
}

\section{Correspondence to:}

Szymon Budrejko, MD, PhD, Department of Cardiology and Electrotherapy, Medical University of Gdansk,

Dębinki 7

80-211 Gdańsk, Poland phone: +48583493910, e-mail:

budrejko@gumed.edu.pl

Copyright by the Author(s), 2021

Kardiol Pol. 2021;

79 (9): 1016-1018;

DOI: 10.33963/KP.a2021.0048

Received:

June 1, 2021

Revision accepted:

June 26, 2021

Published online:

June 27, 2021

\section{INTRODUCTION}

Implantation of a subcutaneous cardioverter-defibrillator (S-ICD) may be used to prevent sudden cardiac death (SCD) due to ventricular arrhythmias in patients not requiring permanent cardiac pacing or antitachycardia pacing $[1,2]$. That method of treatment was first applied in Poland in 2014 [3, 4]. However, it took several years before in 2019 S-ICD became reimbursed to the extent necessary to cover all costs incurred by implant centers. That, in turn, led to an increase in the number of procedures performed in Poland [5]. Currently, there is no report available on how that updated reimbursement regulations might have influenced the qualification procedure, implantation technique, and results in comparison to the preceding period.

The aim of our analysis was to investigate, whether there was any change to indications for S-ICD implantation, operational technique, and patient outcomes over 7 years of S-ICD utilization in Poland.

\section{METHODS}

We compared data collected at two registries in different time intervals: Registry A (September 2014 to December 2015) and Registry B (May 2020 to May 2021). Registry A was a multicenter query reporting data of 18 patients from 5 centers that pioneered S-ICD implantations in Poland [6]. Registry $B$ is a nationwide initiative held by the Heart Rhythm Section of the Polish Cardiac Society [7], and 16 centers performing S-ICD implantations report data on subsequent patients undergoing implantation or exchange of the device. The analysis comprised only 144 patients from Registry B undergoing the first-time implantation of the system. We compared the data describing the general characteristics of patients, underlying diseases, implantation techniques, as well as reasons for the choice of a subcutaneous, instead of a transvenous cardioverter-defibrillator. 
Table 1. Comparison of clinical characteristics of patients in both registries. Registry A - September 2014 to December 2015; Registry B May 2020 to May 2021

\begin{tabular}{|c|c|c|c|}
\hline & Registry A & Registry B & $P$-value \\
\hline \multicolumn{4}{|l|}{ General information } \\
\hline Total number of patients & 18 & 144 & - \\
\hline Age, years, median (IQR) & $39(32-62)$ & $41(31-55)$ & 0.79 \\
\hline Male sex, n (\%) & $10(56)$ & $108(75)$ & 0.1 \\
\hline Sinus rhythm, $\mathrm{n}(\%)$ & $14(78)$ & $135(94)$ & 0.04 \\
\hline Primary prevention, $\mathrm{n}(\%)$ & $4(22)$ & $94(65)$ & $<0.001$ \\
\hline LVEF, \%, median (IQR) & $52.5(45-60)$ & $35(25-60)$ & 0.005 \\
\hline \multicolumn{4}{|l|}{ Underlying disease } \\
\hline Dilated cardiomyopathy, $\mathrm{n}(\%)$ & $3(17)$ & $68(47)$ & 0.02 \\
\hline Ischemic cardiomyopathy, n (\%) & $6(33)$ & $40(28)$ & 0.59 \\
\hline Hypertrophic cardiomyopathy, n (\%) & $2(11)$ & $7(5)$ & 0.26 \\
\hline Arrhythmogenic right ventricular dysplasia, $n(\%)$ & 1 (6) & 0 & 0.11 \\
\hline Long QT syndrome, n (\%) & 1 (6) & $5(3)$ & 0.51 \\
\hline Brugada snyndrome, $\mathrm{n}(\%)$ & $1(6)$ & $3(2)$ & 0.38 \\
\hline Short QT syndrome, n (\%) & $0(0)$ & $2(2)$ & 1 \\
\hline Left ventricular non-compaction, $\mathrm{n}(\%)$ & $0(0)$ & $1(1)$ & 1 \\
\hline Catecholaminergic polymorphic ventricular tachycardia, $\mathrm{n}(\%)$ & $0(0)$ & $1(1)$ & 1 \\
\hline Mitral annular disjunction, $\mathrm{n}(\%)$ & $0(0)$ & $1(1)$ & 1 \\
\hline Congenital heart disease, $\mathrm{n}(\%)$ & $1(6)$ & $2(1)$ & 0.3 \\
\hline Primary ventricular fibrillation, $\mathrm{n}(\%)$ & $3(17)$ & $15(10)$ & 0.43 \\
\hline \multicolumn{4}{|l|}{ Reason for choice of S-ICD vs T-ICD } \\
\hline Young age, $\mathrm{n}(\%)$ & $4(22)$ & 109 (76) & $<0.001$ \\
\hline Risk of infective endocarditis, $n$ (\%) & $11(61)$ & $33(23)$ & 0.001 \\
\hline Recurrent lead failure, $\mathrm{n}(\%)$ & $1(6)$ & $10(7)$ & 1 \\
\hline Lack of venous access, $\mathrm{n}(\%)$ & $8(44)$ & $7(5)$ & $<0.001$ \\
\hline Other, n (\%) & $1(6)$ & $6(4)$ & 0.57 \\
\hline \multicolumn{4}{|l|}{ Implantation procedure } \\
\hline General anesthesia, $\mathrm{n}(\%)$ & $18(100)$ & $107(74 \%)$ & 0.01 \\
\hline Intramuscular pocket, $\mathrm{n}(\%)$ & $13(72)$ & $144(100)$ & $<0.001$ \\
\hline 2-incision technique, $\mathrm{n}(\%)$ & $2(11)$ & $80(56)$ & $<0.001$ \\
\hline Defibrillation test performed, $\mathrm{n}(\%)$ & $18(100)$ & $119(83)$ & 0.08 \\
\hline Defibrillation test successful, $n(\%)$ & $18(100)$ & $119(100)$ & - \\
\hline Complications, n (\%) & $0(0)$ & $3(2)$ & 1 \\
\hline
\end{tabular}

Abbreviations: IQR, interquartile range; LVEF, left ventricular ejection fraction; S-ICD, subcutaneous cardioverter-defibrillator; $T$-ICD, transvenous implantable cardioverter-defibrillator

\section{Statistical analysis}

Continuous variables were presented as the median and interquartile range (IQR) due to non-normal distribution confirmed with the Shapiro-Wilk test. The Mann-Whitney $U$ test was used to compare continuous variables. Categorical parameters were presented as numbers and percentages, and Fisher's exact test was used for comparisons. A P-value of below 0.05 was considered statistically significant. Statistical analysis was performed with the use of Statistica 13.1 software (StatSoft, Tulsa, OK, USA).

\section{RESULTS AND DISCUSSION}

Detailed data of the patients in both groups are presented in Table 1. Inter-group comparisons revealed that during the early period of S-ICD implementation in Poland it was less often implanted in primary prevention of SCD ( $22 \%$ vs $65 \%$; $P<0.001)$, and dilated cardiomyopathy was less frequently the main underlying disease ( $17 \%$ vs $47 \% ; P=0.02)$. Patients in the early group had higher left ventricular ejection fraction (LVEF) (median value, $52.5 \%$ vs $35 \%$; $P=0.005$ ), whereas the main indications prompting the choice of S-ICD were lack of venous access (44\%) and high risk of infective complications (61\%). In the more recent group, young age was the main reason for the choice of S-ICD (76\%). The change in operational technique over time was expressed as a significant increase in the percentage of procedures performed without general anesthesia ( $0 \%$ vs $26 \% ; P=0.01)$. The 2 -incision technique has become more frequently applied instead of the 3 -incision one ( $11 \%$ vs $56 \% ; P<0.001)$, and now the device pocket is more frequently intramuscular than before (72 vs $100 \% ; P<0.001$ ). Defibrillation test tends to be less frequently performed nowadays ( $100 \%$ vs $83 \% ; P=0.08)$. In the patients from Registry B, 3 cases of postoperative complications were reported: pocket hematoma treated conservatively, inadequate shock possibly due to air entrapment in the device connector or pocket, and unilateral lower limb paresis (with no lesions found on imaging of the central nervous system).

During the initial years of S-ICD use in Poland, the number of implanting centers and procedures was limited. It resulted from the high cost of the system and troublesome reimbursement procedure. Therefore, S-ICD implantation 
was reserved for secondary prevention of SCD and patients not eligible for a transvenous system (either with limited vascular access or high risk of infective complications) because only in such cases the implanting center was certain it would be fully reimbursed. Once complete reimbursement was introduced, the method became more applicable in the primary prevention of SCD, and the patient's young age might have become an indication for the choice of S-ICD. That selection factor became dominant, which brought Polish data closer to European reports [8]. Novel operational techniques reported in the literature, such as regional anesthesia, 2-incision technique, and intramuscular pocket [9-12], have been introduced in Polish centers ever since. Those techniques have become most common, and our results suggest that general anesthesia may be replaced by local and regional anesthetic techniques soon. Our analysis shows that in many cases (17\% in the Registry B) the defibrillation test is currently waived. It may result from the high efficacy of S-ICD in the termination of ventricular fibrillation, which reached $100 \%$ of performed tests in both registries. Alternatively, it may be due to the concerns about the safety of inducing ventricular fibrillation in patients with more reduced LVEF, as a tendency to implant S-ICD in patients with more severe LVEF impairment was observed in Registry B, as compared to Registry A (median LVEF 35\% vs $52.5 \%$, respectively). Notably, that did not significantly increase the complication rate, which remains below $2 \%$ in our data and is lower than reported by other groups [13].

Our analysis confirms the increasing role of S-ICD as a method of primary prevention of SCD in Poland. Recent administrative regulations resulted in a change of profile of patients qualified for the procedure. Currently, the main reason for the choice of S-ICD is the young age of a patient. A tendency to incorporate new operational techniques used in European centers is observed, with no increase in the perioperative complication rate. The influence of updated reimbursement regulations on the use of S-ICD in Poland suggests that other modern methods might be successfully introduced on condition that they are accompanied by clear regulations covering all the costs borne by the implanting centers.

\section{Article information}

Conflict of interest: MK received proctoring and lecturer fees from Boston Scientific. AP received lecturer's fees from Medtronic Polska, Biotronik Polska and consultancy fees from Medtronic Polska. KK received proctoring, and lecturer fees from Boston Scientific. MO: proctorship agreement with Boston Scientific. PS received lecturer's fees for Abbott, Biotronik, Boston Scientific, Medtronic, and consultancy fees for Biotronik, Boston Scientific. ASo: consultancy agreement with Boston Scientific. MG received consultant and lectures fees from Medtronic, Biotronik, Abbott and Boston Scientific. DJ received lecturer fees from Boston Scientific. ST received consultancy fee from Boston Scientific. $\mathrm{SB}, \mathrm{WK}, \mathrm{MG}, \mathrm{JR}, \mathrm{MJ}, \mathrm{ZO}, \mathrm{JZK}, \mathrm{ASt}, \mathrm{MO}$ declared no conflict of interest.

Open access: This article is available in open access under Creative Common Attribution-Non-Commercial-No Derivatives 4.0 International (CC BY-NC-ND 4.0) license, allowing to download articles and share them with others as long as they credit the authors and the publisher, but without permission to change them in any way or use them commercially. For commercial use, please contact the journal office at kardiologiapolska@ptkardio.pl.

How to cite: Kempa M, Przybylski A, Budrejko S, et al. Evolution of implantation technique and indications for a subcutaneous cardioverter-defibrillator over 7 years of experience in Poland. Kardiol Pol. 2021; 79(9): 1016-1018, doi: 10.33963/KP.a2021.0048.

\section{REFERENCES}

1. Priori SG, Blomström-Lundqvist C, Mazzanti A, et al. 2015 ESC Guidelines for the management of patients with ventricular arrhythmias and the prevention of sudden cardiac death: The Task Force for the Management of Patients with Ventricular Arrhythmias and the Prevention of Sudden Cardiac Death of the European Society of Cardiology (ESC)Endorsed by: Association for European Paediatric and Congenital Cardiology (AEPC). Eur Heart J. 2015; 36(41): 2793-2867, doi: 10.1093/eurheartj/ehv316, indexed in Pubmed: 26320108.

2. Al-Khatib SM, Stevenson WG, Ackerman MJ, et al. 2017 AHA/ACC/HRS guideline for management of patients with ventricular arrhythmias and the prevention of sudden cardiac death: Executive summary: A Report of the American College of Cardiology/American Heart Association Task Force on Clinical Practice Guidelines and the Society. Heart Rhythm. 2018; 15(10): e190-e252, doi: 10.1016/j.hrthm.2017.10.035, indexed in Pubmed: 29097320.

3. Kaczmarek K, Kempa M, Grabowski M, et al. A subcutaneous implantable cardioverter-defibrillator - the first implantation in Poland. Kardiol Pol. 2015; 73(1): 62-771, doi: 10.5603/KP.2015.0010, indexed in Pubmed: 25625342.

4. Kempa M, Budrejko S, Sławiński G, et al. Subcutaneous implantable cardioverter-defibrillator (S-ICD) for secondary prevention of sudden cardiac death. Arch Med Sci. 2016; 12(5): 1179-1180, doi: 10.5114/aoms.2016.61921, indexed in Pubmed: 27695509.

5. Regulation of the Minister of Health of 9 January 2019 amending the regulation on guaranteed services in the field of hospital treatment. The Journal of Laws of the Republic of Poland: item 77 [text in Polish].

6. Kaczmarek K, Kempa M, Grabowski M, et al. Multicentre early experience with totally subcutaneous cardioverter-defibrillators in Poland. Arch Med Sci. 2020; 16(4): 764-771, doi: 10.5114/aoms.2019.83817, indexed in Pubmed: 32542076.

7. Kempa M, Przybylski A, Budrejko S, et al. Multicenter Registry of Subcutaneous Cardioverter-Defibrillator Implantations - preliminary report. Kardiol Pol. 2021; 79(6): 697-699, doi: 10.33963/KP.a2021.0002, indexed in Pubmed: 34013514.

8. Jędrzejczyk-Patej E, Boveda S, Kalarus Z, et al. Factors influencing the use of subcutaneous or transvenous implantable cardioverter-defibrillators: results of the European Heart Rhythm Association prospective survey. Europace. 2018; 20(5): 887-892, doi: 10.1093/europace/euy009, indexed in Pubmed: 29432525.

9. Droghetti A, Basso Ricci E, Scimia P, et al. Ultrasound-guided serratus anterior plane block combined with the two-incision technique for subcutaneous ICD implantation. Pacing Clin Electrophysiol. 2018; 41(5): 517-523, doi: 10.1111/pace.13318, indexed in Pubmed: 29493802.

10. van der Stuijt W, Baalman SWE, Brouwer TF, et al. Long-term follow-up of the two-incision implantation technique for the subcutaneous implantable cardioverter-defibrillator. Pacing Clin Electrophysiol. 2020; 43(12): 1476-1480, doi: 10.1111/pace.14022, indexed in Pubmed: 32720398.

11. Quast AFBE, Baalman SWE, Brouwer TF, et al. A novel tool to evaluate the implant position and predict defibrillation success of the subcutaneous implantable cardioverter-defibrillator: The PRAETORIAN score. Heart Rhythm. 2019; 16(3):403-410, doi: 10.1016/j.hrthm.2018.09.029, indexed in Pubmed: 30292861.

12. Kempa M, Sterliński M, Mitkowski $P$, et al. Safety issues in selected patients implanted with Boston Scientific EMBLEM subcutaneous cardioverter defibrillator systems. Kardiol Pol. 2021; 79(2): 223-224, doi: 10.33963/KP.15833, indexed in Pubmed: 33635036.

13. Boersma LV, El-Chami MF, Bongiorni MG, et al. Understanding outcomes with the EMBLEM S-ICD in primary prevention patients with low EF study (UNTOUCHED): clinical characteristics and perioperative results. Heart Rhythm. 2019; 16(11): 1636-1644, doi: 10.1016/j.hrthm.2019.04.048, indexed in Pubmed: 31082539. 